\title{
High School Students' Critical Thinking Related to Their Metacognitive Self-Regulation and Physics Self-Efficacy Beliefs
}

\author{
Deniz Gurcay ${ }^{1}$, Hatice Ozturk Ferah ${ }^{1}$ \\ ${ }^{1}$ Hacettepe University, Ankara, Turkey \\ Correspondence: Deniz Gurcay Hacettepe University, Ankara, Turkey. \\ Received: February 5, 2018 \\ Accepted: March 9, 2018 \\ Online Published: March 18, 2018 \\ doi:10.11114/jets.v6i4.2980 \\ URL: https://doi.org/10.11114/jets.v6i4.2980
}

\begin{abstract}
The purpose of this study is to examine the relationships between ninth grade students' metacognitive self-regulation skills and physics self-efficacy beliefs and their critical thinking. To this end, 162 students attending the ninth grade participated in the study. Critical thinking scale, metacognitive self-regulation scale and physics self-efficacy scale were used as data collection tools in the study. Data were analyzed by descriptive statistics, pearson product moment correlation analysis, and stepwise multiple regression analysis. According to descriptive analysis results the students' critical thinking, metacognitive self-regulation and physics self-efficacy beliefs were high. Moreover, stepwise multiple regression analysis revealed that the students' metacognitive self-regulation and physics self-efficacy belief scores were significant predictors of their critical thinking scores, explaining $55 \%$ of the variance of critical thinking scores. In addition, it was also determined that the main variable that best explained critical thinking was metacognitive self-regulation, explaining $53 \%$ of variance.
\end{abstract}

Keywords: critical thinking, metacognitive self-regulation, physics self-efficacy belief

\section{Introduction}

In today's fast-paced knowledge, students need to have some skills in selecting useful information, evaluating the truth of information, and making decisions. Critical thinking is an important skill in decision-making process of students. Currently, one of the main aims of science educators is to improve students' critical thinking skills. In this context, this study focus on the relationship between critical thinking metacognitive self regulation and self efficacy.

In today's educational approaches in which learners actively participate in the learning process, students need to make sense of new knowledge by associating it with previously learned knowledge instead of memorizing it, and question this knowledge. Therefore, it is obvious that students need to be gained higher order cognitive skills such as problem solving, analyzing, evaluation, creative thinking and decision making. Likewise, learners also need to have critical thinking skills such as predicting, induction, deduction and reasoning. According to philosophers of education, critical thinking is not only one of the approaches that could be used in the education process but also an indispensable part of education (Norris, 1985). However, critical thinking is important not only in academic learning environments but also in daily life. For example, critical thinking is necessary for individuals to adjust to the world what is developing in parallel to the innovations in science and technology.

Several researchers have defined critical thinking. According to Ennis (1987, p.10) "Critical thinking is reasonable, reflective thinking that is focused on deciding what to believe or do". In addition, critical thinking involves problem solving processes such as constructing hypotheses regarding problems and suggesting ways of solutions, and collecting data (Lewis \& Smith, 1993). Facione (1984) defines critical thinking as a process of argumentation and evaluation. Moreover, he associates the process of argumentation and evaluation with problem solving steps involving forming hypotheses, testing hypotheses and solving problem. Likewise, Linn, (2000) defines critical thinking as skills of using the knowledge they have gained in the past when they encounter a problem, making judgments and making assessments according to certain criteria. Critical thinking is a cognitive process that requires learners to understand the phenomena and ideas around them using prior knowledge as criteria. To what extent individuals will be successful in this process depends on how enthusiastic they are. In other words, individuals' skills and tendencies are important in this process.

Critical thinking is a way of thinking that is consciously controlled and in which learners assume responsibility of their own learning (Paul, 1996, Smith, 2003). Kuhn, (1999) emphasized that critical thinking is linked to metacognition in which individuals have knowledge of their cognition and monitor their thinking, evaluate their efforts in this process 
and judge accuracy of their decisions. Some studies indicate that critical thinking is associated with metacognitive self-regulation (Uzuntiryaki \& Capa, 2013).

While systems based on information and technology are developing with each passing day, individuals best trained for the future will undoubtedly be those who can use self-regulation skills most. (Andrew and Vialle, 1998). Metacognitive strategies are described as strategies of reflecting over learning; planning, comprehending and understanding the learning process as well as evaluating the self after the learning activity (Un, 2003). One of the key factors to success depends on learners' use of metacognitive strategies. According to Pintrich (2000), metacognitive self-regulation is an active and structural process where learners determine their own learning objectives, and regulate their motivation and behaviors. Moreover, metacognitive self-regulation is also a kind of control mechanism that individuals have over their own learning (Talbot, 1997). In order for metacognitive self-regulation strategies to be effective, first learners need to determine their objectives. Then, to what extent objectives have been attained after the efforts spent need to be evaluated by the learner. If an error is detected anywhere as a result of the evaluation, necessary regulations need to be made. All of these strategies are metacognitive learning strategies, which are control strategies that learners have formed over to monitor their learning (Zimmerman, 1990).

One of the variables which is argued to be associated with critical thinking is self-efficacy (Bandura, 1997). Bandura (1997, p.3) defined self-efficacy as "beliefs in one's capabilities to organize and execute the courses of action required to produce given attainments". Self-efficacy belief affects the level of effort students spend on a task and their success level. Self-efficacy belief is specific to the field and the situation (Schwarzer, 1993). Bandura (1997) emphasizes that individuals may possess self-efficacy belief in different fields and at different levels. Students who with a high level of self-efficacy belief in science courses prefer to deal with more difficult problems, make more effort to succeed, and are persistent to complete a task assigned to them even if they encounter obstacles (Pajares, 1996). Besides, they also use self-regulation strategies to be successful (Schunk \& Pajares, 2005). There is a positive correlation between belief in self-efficacy and self-regulation (Schunk \& Ertmer, 2000, Zimmermann, Bandura, Martinez, 1992). On the other hand, students with a low level of self-efficacy belief in science courses prefer easy tasks, make less effort, have difficulty adjusting to classes at school and exhibit lower academic achievement (Schunk, 1991). Bandura (1997) defined four fundamental sources of self-efficacy belief (mastery experience, vicarious experience, social persuasion and physiological states) and emphasized that self-efficacy could be improved.

Recent studies have shown that students with critical thinking skill exhibit a questioning approach in both reaching information and assessing the accuracy of information. Students with advanced critical thinking skills are more successful in making decisions (Zoller \& Pushkin, 2007) and checking their own learning processes. However, research results indicate that critical thinking is at a rather low level even among university students (Halpern, 1998). From this perspective, it is important to determine the variables predicting critical thinking. The objectives in the Physics course have been prepared with a view to develop students' critical thinking skills within the framework of skills of scientific processes, use knowledge of Physics in daily life, and associating science with technology, society and environment (Ministry of National Education, 2017). Therefore, since Physics is a field that requires critical thinking by virtue of its nature, advanced critical thinking skills will enable students to learn Physics better. The aim of this study is to investigate to what extent ninth grade students' metacognitive self-regulation and physics self-efficacy beliefs predict their critical thinking. To achieve this aim, the following sub-problems have been determined for the study:

1. Is there a relationship among ninth grade students' critical thinking, metacognitive self-regulation and physics self -efficacy beliefs?

2. What are the contributions of metacognitive self-regulation and physics self-efficacy beliefs on critical thinking?

3. Which variable best predicted students' critical thinking?

\section{Methodology}

The survey model was used in this study because the relationships between ninth grade students' critical thinking, metacognitive self-regulation and physics self-efficacy beliefs are investigated (Fraenkel \& Wallen, 2009).

\subsection{Participants of the Study}

This study was carried out with 162 ninth grade students attending an Anatolian High School in a province in the Southeast Anatolia region of Turkey. Turkey has a centralized educational system. Students in Turkey are placed to Anatolian High Schools through a nation-wide high school examination and high school curricula regulated by the Ministry of National Education. Participants were selected by using convenience sampling.

102 of the students participating in the study were female whereas 60 of them were male. The ages of the students participating in the study varied between 14 and 16 . The physics course grades of $47 \%$ of the participating students were 50 or below whereas those of $53 \%$ of them were 50 or above. The socio-economic levels of the students were medium. 


\subsection{Data Collection Tools}

Critical Thinking, metacognitive self-regulation and self-efficacy belief sub-dimensions of the Motivational Strategies for Learning Questionnaire, which was developed by Pintrich, Smith, Garcia and McKeachie (1991), were used in the study as the data collection tool. Motivational Strategies for Learning Questionnaire was adapted to Turkish by Sungur (2004). The Critical Thinking scale was used to measure to what extent students were able to use their previous information to solve problems, make decisions and make critical evaluations. The Metacognitive Self-Regulation Scale, on the other hand, was used to measure to what extent students used the planning, self-monitoring and regulation activities in their learning processes. The Self-Efficacy Belief Scale was used to measure students' beliefs that they could learn physics. The items on the Self-Efficacy Belief Scale were reorganized as to be related to physics and named Physics Self-Efficacy Belief Scale. The 5-item Critical Thinking Scale, the 12-item Metacognitive Self-Regulation Scale and the 8-item Physics Self-Efficacy Belief Scale were rated on a seven point Likert scale ranging from not at all true of me (1) to very true of me. Minimum and maximum scores that the students could receive from the Critical Thinking Scale varied between 5 and 35. The minimum and maximum scores they could receive from the Metacognitive Self-Regulation Scale varied between 12 and 84. The minimum and maximum scores they could receive from the Physics Self-Efficacy Belief Scale varied between 8 and 56.

Cronbach Alpha reliability coefficients of the original scales were .80 for the Critical Thinking Scale, .79 for the Metacognitive Self-Regulation Scale and .93 for the Self-Efficacy Belief Scale (Pintrich, et al., 1991). Cronbach Alpha reliability coefficients of the scales adapted to Turkish, on the other hand, were .81 for the Critical Thinking Scale, $.81, .81$ for the Metacognitive Self-Regulation Scale and .89 for the Self-Efficacy Belief Scale (Sungur, 2004). In this study, Cronbach Alpha reliability coefficient was calculated to be .75 for the Critical Thinking Scale, .73 for the Metacognitive Self-Regulation Scale and .84 for the Physics Self-Efficacy Belief Scale. The testing tools were administered to the participants by the researchers on a voluntary basis. Participants were given $20 \mathrm{~min}$. to respond the scales.

\subsection{Data Analysis}

Since the present study investigated to what extent variables of metacognitive self-regulation and physics self-efficacy beliefs predicted critical thinking, descriptive statistics, pearson product moments correlation analysis and stepwise multiple regression analysis were used for data analysis.

\section{Results}

Descriptive statistics were used to determine the high school ninth grade students' critical thinking, metacognitive self-regulation and physics self-efficacy belief levels. Mean, standard deviation, skewness and kurtosis results for these variables presented in Table 1 .

Table 1. Descriptive statistics for the scores of critical thinking, metacognitive self-regulation and physics self-efficacy belief

\begin{tabular}{llll}
\hline & Critical & Metacognitive & Physics \\
& Thinking & Self-Regulation & Self-Efficacy Belief \\
\hline Mean & 23.61 & 58.91 & 41.41 \\
Std. Dev. & 6.35 & 11.27 & 8.96 \\
Skewness & -.66 & -.94 & -.95 \\
Kurtosis & .28 & .76 & 1.27 \\
$\mathrm{~N}$ & 162 & 162 & 162 \\
\hline
\end{tabular}

Results of the descriptive analysis indicate that critical thinking mean scores of the ninth grade students are high. In other words, results of the descriptive analysis show that ninth grade students' skills of problem solving, reasoning and making decision on the basis of criteria are at a high level. Likewise, metacognitive self-regulation mean scores of the ninth grade students are also high. That is to say, students' levels of control over their own learning processes are high. The students' physics self- efficacy belief mean scores are also high. This means that no matter how hard a task is when learning physics, the students' belief that they can manage it is high.

Stepwise multiple regression analysis was conducted to determine to what extent students' metacognitive self-regulation scores and physics self-efficacy belief scores predicted their critical thinking scores. Before embarking on the analysis, assumptions of stepwise multiple regression were tested. Tabachnick \& Fidel (1996) stated that to determine the sample size, $\mathrm{N} \geq 50+8 \mathrm{~m}$ (N: Number of participants; m: Number of independent variables). Consequently, since $162 \geq 66$, it was decided that sample size was sufficient to conduct stepwise multiple regression. Other assumptions of stepwise multiple regression, namely multicolinearity, normality, linearity and homoscedasticity were checked. No violation of the assumptions was detected.

Pearson product moment correlation analysis results calculated for the relationship between students' critical thinking, metacognitive self-regulation and physics self-efficacy belief scores are given in Table 2. Since independent variables are not highly correlated with each other, there was, no violation of the multicolinearity assumption (Table 2). Moreover, 
there were no VIF values above 10 (Table 3). Table 2 shows that there is a medium level, positive and significant relationship between the students' critical thinking scores and their physics self-efficacy belief scores. On the other hand, a high level, positive and significant relationship was detected between the students' critical thinking scores and metacognitive self-regulation scores. Moreover, a medium level, positive and significant relationship was found between the students' metacognitive self-regulation scores and physics self-efficacy beliefs.

Table 2. Pearson Correlations among scores of critical thinking, metacognitive self-regulation and physics self-efficacy belief

\begin{tabular}{lcc}
\hline & Critical Thinking & Metacognitive Self-Regulation \\
\hline Metacognitive Self-Regulation & $.73^{*}$ & \\
Physics Self-Efficacy Belief & $.52^{*}$ & $.58^{*}$ \\
\hline
\end{tabular}

*Correlation is significant at the .05 level.

Stepwise multiple regression analysis was used to explore the contributions of students' metacognitive self-regulation scores and physics self-efficacy belief scores to their critical thinking scores. Results of this analysis presented in Table 3. According to the results of the analysis the variable that best predicted critical thinking was determined to be students' metacognitive self-regulation scores $\left(\mathrm{R}^{2}=.53 ; \mathrm{F}(1,160)=180.35, \mathrm{p}<.05\right)$. When students' physics self-efficacy belief scores was added to the model in addition to the metacognitive self-regulation, it was found that both variables have significant contributions $\left(\mathrm{R}^{2}=.55, \mathrm{~F}(2,159)=95.20, \mathrm{p}<.05\right)$. It was determined that the entire model accounted for $55 \%$ of the variance for critical thinking. The direction of the relationship between critical thinking and physics self-efficacy belief and metacognitive self-regulation is positive (Table 3). Thus, as metacognitive self-regulation and physics self-efficacy belief scores increase, so do critical thinking scores.

Table 3. Stepwise multiple regression results

\begin{tabular}{lcccc}
\hline \multicolumn{1}{c}{ Model } & B & t & Sig. & $\begin{array}{c}\text { Collinearity Statistics } \\
\text { VIF }\end{array}$ \\
\hline 1 & & & & \\
Metacognitive Self-Regulation & .41 & 13.43 & .000 & 1.000 \\
\hline 2 & & & & \\
Metacognitive Self-Regulation & .36 & 9.74 & .000 & 1.511 \\
Physics Self-Efficacy Belief & .11 & 2.30 & .023 & 1.511 \\
\hline
\end{tabular}

\section{Conclusion, Discussion and Recommendations}

The purpose of this study is to investigate to what extent the ninth grade students' critical thinking skills were predicted by their metacognitive self-regulation and physics self-efficacy beliefs. The ninth grade students' critical thinking, metacognitive self-regulation and physics self-efficacy belief levels are high. The fact that the students' critical thinking levels are high may be interpreted to mean that they can make predictions for a specific purpose, make accurate inferences and thus make correct decisions. On the other hand, the fact that the students' metacognitive self-regulation skills are high indicates that they have a high level control over their own learning processes. Likewise, the students' high physics self-efficacy beliefs show that no matter how difficult a physics task may be, the students' belief that they can do it is high.

When the results of pearson product moment correlation analysis were examined, it was found that a high level, positive and significant correlation was found between critical thinking and metacognitive self-regulation. This indicates that as the students' critical thinking levels increased, they set more learning objectives for themselves, monitored their learning processes and made use of the strategies aimed at raising their learning quality by judging themselves. On the other hand, a medium level, positive and significant correlation was determined between critical thinking and physics self-efficacy belief. This indicates that beliefs of students who use high order cognitive skills such as making predictions, analysis and evaluations regarding the fact that they can be successful in tasks related to physics are at a medium. Several studies have emphasized that students with high levels of self-efficacy beliefs are more inclined to critical thinking (Bandura, 1997, Phan, 2009). A medium level, positive and significant correlation was found between the students' metacognitive self-regulation and physics self-efficacy beliefs. According to this, it was found that the students who had control over their own learning processes in the physics classes had a medium level belief in themselves that they could overcome the difficulties they might encounter in these classes and reach the academic goals they have set for themselves. In the same manner, results of various studies point to a positive correlation between self-regulation and self-efficacy (Schunk \&Ertmer, 1999; Schnoll \& Zimmermann, 2001; Sungur, 2007).

It is seen as a result of the stepwise multiple regression analysis that ninth grade students' metacognitive self-regulation scores and physics self-efficacy belief scores explained $55 \%$ of the variance for their critical thinking scores. In addition, the most important variable that predicted the critical thinking was metacognitive self-regulation, explaining $53 \%$ of variance. It can be concluded that students with metacognitive self-regulation skills took responsibility for their own learning and developed a more questioning approach in reaching information and constructing information. 
Students' forming a control mechanism over their own learning and making use of several strategies play a key part in their acquisition of critical thinking. This result is also supported by studies in the relevant literature (Phan, 2010; Pintrich, Smith, Garcia \& McKeachie, 1993; Uzuntiryaki \& Capa, 2013). On the other hand, it was seen that the students who had confidence in their efforts and believed that they could be successful while they were studying physics exhibited more questioning and deductive approaches.

In conclusion, it was found that students' metacognitive self-regulation had a significant role in developing their critical thinking skills. This means that students who take responsibility for their own learning and guide their learning processes in a conscious manner will be individuals who can think critically. Likewise, students' belief that they could be successful in a physics task no matter how difficult it might be indicating that they made logical inferences while they were learning and would exhibit a questioning approach. Since self-efficacy belief is a construct that can be improved, it is suggested that teachers should take into consideration sources of self-efficacy and thus try to develop students' self-efficacies.

Importance of cognitive and metacognitive self-regulation strategies in education has been demonstrated in many studies in the relevant literature (Pintrich \& De Groot, 1990; Fuchs et al, 2003). Development of the said skills means students' gaining critical thinking skills, which in turn means better learning quality. The interpretation of the results of this study is limited because the participants were restricted to the 162 ninth grade high school students. For this reason, these findings may not be completely generalizable to the broader community based on this study alone.

\section{References}

Andrew, S., \& Vialle, W. (1998). Nursing Students self efficacy, self regulated learning and academic performance in science. Nursing Times, 76, 427-435.

Bandura, A. (1997). Self-efficacy: The exercise of control. W.H. Freeman and Company, New York.

Ennis, R. (1987). A taxonomy of critical thinking dispositions and abilities. In J.B. Baron \& R. Sternberg (Eds.), Teaching thinking skills: Theory and practice (pp. 9-26). New York: W.H. Freeman \& Co.

Facione, P. A. (1984). Toward a theory of critical thinking. Liberal Education, 70, 253-261.

Fraenkel, J. R., \& Wallen, N. E. (2009). How to design and evaluate research in education. Seventh Edition, McGraw-Hill, New York, 642.

Fuchs, L. S., Fuchs, D., Prentice, K., Burch, M., Hamlett, C. L., Owen, R., \& Schroeter, K. (2003). Enhancing third-grade student's mathematical problem solving with self regulated learning strategies. Journal of Educational Psychology, 95(2), 306-315. https://doi.org/10.1037/0022-0663.95.2.306

Halpern, D. F. (1998). Teaching critical thinking for transfer across domains. American Psychologist, 53, 449-455. https://doi.org/10.1037/0003-066X.53.4.449

Kuhn, D. (1999). A developmental model of critical thinking. Educational Researcher, 28(1), 16-26. https://doi.org/10.3102/0013189X028002016

Lewis, A., \& Smith, D. (1993). Defining Higher Order Thinking. Theory into Practice, 32(3), 131-137. https://doi.org/10.1080/00405849309543588

Linn, M. C. (2000). Designing the knowledge integration environment. International Journal of Science Education, 22, 781-796. https://doi.org/10.1080/095006900412275

Ministry of National Education, (2017). Secondary Physics Program. Chairman of the Board of Education. Retrieved from http://mufredat.meb.gov.tr/ProgramDetay.aspx?PID=351

Norris, S. P. (1985). Synthesis of research on critical thinking. Educational Leadership, 42(8), 40-45.

Pajares, F. (1996). Self-Efficacy Beliefs in Academic Settings. Review of Educational Research, 66(4), 543-578. https://doi.org/10.3102/00346543066004543

Paul, R. (1996). Critical thinking workshop handbook. Rohnert Park, CA: Centre for Critical Thinking, Sanoma State University.

Phan, H. P. (2009). Relations between goals, self-efficacy, critical thinking, and deep processing strategies: A path analysis. Educational Psychology, 29, 777-799. https://doi.org/10.1080/01443410903289423

Phan, H. P. (2010). Students' academic performance and various cognitive processes of learning: An integrative framework and empirical analysis. Educational Psychology, 30, 297-322. https://doi.org/10.1080/01443410903573297

Pintrich, P. R., \& De Groot, E. (1990). Motivational and self regulated learning components of classroom academic performance. Journal of Educational Psychology, 82(1), 33-40. https://doi.org/10.1037/0022-0663.82.1.33 
Pintrich, P. R., Smith, D. A. F., Garcia, T., \& McKeachie, W. J. (1991). A manual for the use of the motivated strategies for learning questionnaire (MSLQ). Michigan: School of Educational Building. The University of Michigan.

Pintrich, P. R., Smith, D. A., Garcia, T., \& McKeachie, W. J. (1993). Reliability and predictive validity of the Motivated Strategies for Learning Questionnaire (MSLQ). Educational and Psychological Measurement, 53, 801-813. https://doi.org/10.1177/0013164493053003024

Pintrich, R. R. (2000). The role of goal orientation in self-regulated learning. In Boekaerts, M., Pintrich, P. R., ve Zeidner, M. (Eds.), Handbook of Self- regulation, (pp. 451-501), San Diego, CA: Academic Press. https://doi.org/10.1016/B978-012109890-2/50043-3

Schnoll, R., \& Zimmerman, B. J. (2001). Self-regulation training enhances dietary self-efficacy and dietary fiber consumption. Journal of the American Dietetic Association, 101, 1006-1011. https://doi.org/10.1016/S0002-8223(01)00249-8

Schunk, D. H. (1991). Self-efficacy and Academic Motivation. Educational Psychologist, 26, 207-231. https://doi.org/10.1080/00461520.1991.9653133

Schunk, D. H., \& Ertmer, P. A. (2000). Self-regulation and academic learning. In M. Boekaerts, P. R. Pintrich, ve M. Zeidner (Eds), Handbook of self-regulation (pp, 631-649). San Diego, CA: Academic Press. https://doi.org/10.1016/B978-012109890-2/50048-2

Schunk, D. H., \& Ertmer, R A. (1999). Self-regulatory processes during computer skill acqui- sition: Goal and self-evaluative influences. Journal of Educational Psychology, 91, 251-260. https://doi.org/10.1037/0022-0663.91.2.251

Schunk, D. H., \& Pajares, F. (2005). Competence beliefs in academic functioning. In A. J. Elliot \& C. Dweck (Eds.), Handbook of competence and motivation (pp. 85-104). New York: Guilford Press.

Schwarzer, R. (1993). General perceived self-efficacy in 14 cultures. Retrieved from http://Web.Fu-Berlin.De/Gesund/Publicat/Ehpscd/Health/World14.Htm

Smith, G. F. (2003). Beyond critical thinking and decision making: teaching business students how to think. Journal of Management Education, 27(1), 24-51. https://doi.org/10.1177/1052562902239247

Sungur, S. (2004). The implementation of problem based learning in high school biology courses. Unpublished doctoral dissertation, Middle East Technical University, Turkey.

Sungur, S. (2007). Modeling the relationships among students' motivational beliefs, metacognitive strategy use, and effort regulation. Scandinavian Journal of Educational Research, 51, 315-326. https://doi.org/10.1080/00313830701356166

Tabachnick, B. G., \& Fidell, L. S. (1996). Using multivariate statistics. (3th ed.). NY: HarperCollins.

Talbot, G. L. (1997). Can self-regulated learning be taught to college students? Washington, DC: U.S. Department of Education.

Un, A. K. (2003). Etkili Öğrenme ve Öğretme (Effective Learning and Teaching). İzmir: Eğitim Dünyası Yayınları.

Uzuntiryaki-Kondakci, \& Capa-Aydin (2013). Predicting critical thinking skills of university students through metacognitive self-regulation skills and chemistry self-efficacy. Kuram Ve Uygulamada Egitim Bilimleri, 13(1), 661-670.

Zimmerman, B. J. (1990). Self-regulated learning and academic achievement: An overview. Educational Psychologist, 25(1), 3-7. https://doi.org/10.1207/s15326985ep2501_2

Zimmerman, B. J., Bandura, A., \& Martinez-Pons, M. (1992). Self- motivation for academic attainment: the role of self-efficacy beliefs and personal goal-setting. American Educational Research Journal, 29(3), 663-676. https://doi.org/10.3102/00028312029003663

Zoller, U., \& Pushkin, D. (2007). Matching higher-order cognitive skills (HOCS) promotion goals with problem-based laboratory practice in a freshman organic chemistry course, Chem. Educ. Res. Pract., 8, 153- 171. https://doi.org/10.1039/B6RP90028C

\section{Copyrights}

Copyright for this article is retained by the author(s), with first publication rights granted to the journal.

This is an open-access article distributed under the terms and conditions of the Creative Commons Attribution license which permits unrestricted use, distribution, and reproduction in any medium, provided the original work is properly cited. 